\title{
Accumulation of physical activity for health gains: what is the evidence?
}

\author{
Adrianne E Hardman
}

\section{Introduction}

Physical activity is recognised as an important component of a healthy lifestyle, by the population at large as well as by scientists and clinicians. Nevertheless, most adult men and women in this country are physically inactive. ${ }^{1}$ To alleviate the considerable public health burden of this level of inactivity requires nothing less than a major shift of behaviour to a more active style of living. ${ }^{2}$ A start has been made with efforts to develop a physical activity strategy for England ${ }^{3}$ and the Health Education Authority's campaign "Active Living". Both initiatives reflect a change of emphasis in making recommendations for physical activity. Traditionally, recommendations were for 20-60 minutes of moderate to high intensity endurance-type exercise performed three or more times per week. By contrast, recent consensus statements from expert bodies in the United States (on which the United Kingdom recommendations are modelled) encompass the notion that many health gains may be acquired through moderate intensity physical activities outside formal exercise programmes. ${ }^{4-6}$ This review is concerned with one particular aspect of these recommendations, namely that one effective pattern of physical activity is several short sessions during the day.

\section{Methods}

A search was made through Medline from 1970 to the present, using combinations of the following terms: accumulation, exercise, training, intermittent, continuous, short bout(s), long bout(s), session(s), physical activity recommendations, and splitting distance/time. A large number of publications were found through use of the terms intermittent and continuous but, with one exception, these compared the effects of training through rather long bouts of exercise with those of "interval training"- that is, high intensity efforts separated by brief recovery periods but within the same session. As the key feature of accumulating exercise is performance of several short separate exercise sessions throughout the day, this literature was not pursued further. Only five original papers were found describing studies comparing the effects of increasing levels of physical activity through several short sessions of exercise per day with those from one longer session. Because of the paucity of literature addressing this topic specifically, additional indirect evidence has been invoked (using a personal library) in evaluating the rationale for the proposition that physical activity accumulated through the day confers health benefits.

\section{Observational studies}

Guidelines for the amount of exercise needed to confer health gains were originally developed from two lines of evidence: first, epidemiological findings of a lower risk of coronary heart disease and premature mortality in men who engaged in considerable amounts of physical activity; and second, the literature describing the amount and type of exercise needed to increase endurance fitness (usually assessed as maximal oxygen uptake ( $\left.\dot{\mathrm{V}}_{2} \mathrm{MAx}\right)$ ) in healthy adults. The common feature was planned exercise or training of a fairly vigorous nature. In fact, in one landmark study of English civil servants, only "vigorous" exercise was associated with a lower risk of heart attack. Thus the accepted view was that activities that increase fitness confer many, maybe most, health benefits. This view is probably sound as studies that have related physical fitness to allcause mortality and cause specific mortality and morbidities have shown. ${ }^{7-10}$

However, although the epidemiological evidence undoubtedly shows that engaging in activity sufficient to improve fitness, including vigorous sports, is associated with low risk, it also shows that activity unlikely to improve fitness may also be effective. For example, some studies have shown a strong inverse association between some measure of the total amount of energy expended in leisure time physical activity and cardiovascular ${ }^{11}$ or all-cause mortality, ${ }^{11}{ }^{12}$ incidence of type II diabetes, ${ }^{13}$ hypertension, ${ }^{14}$ and site specific cancers. ${ }^{15}{ }^{16}$ In the British regional heart study, the inverse relation between physical activity index and risk of ischaemic heart disease was not reduced by excluding all men who reported doing vigorous sporting activity; thus men who regularly engaged in gardening, do it yourself, and "pleasure walking" experienced a reduced rate of heart attack. ${ }^{17}$

In many of these studies, the type of activity associated with more favourable health outcomes is likely to have been performed at least partly on an intermittent basis. These include walking, climbing stairs, gardening, ${ }^{12} 1819$ and, in one recent Finnish study, repair work. ${ }^{11}$ Stair climbing - surely almost never performed in long continuous sessions - has been associated with a decreased risk of premature death; men who climbed fewer than 20 flights of stairs a week had a $23 \%$ higher risk than men who climbed more. ${ }^{20}$

Walking, particularly when undertaken for personal transport, is often performed in rather short sessions at intervals of some hours. The amount of walking has been associated with a lower risk of all-cause mortality in middle aged men $(21 \%$ lower risk as distance increased
Accepted for publication 1 December 1998 
from less than 3 miles to 9 miles or more a week), ${ }^{12}$ in retired men (59\% lower risk for those who walked 2 miles or more a day, compared with those who walked less than 1 mile a day), ${ }^{21}$ and in women ( $60 \%$ lower risk in those expending energy equivalent to walking for about 45 minutes three times a week). ${ }^{22}$

Data from the Harvard alumni show an inverse relation between energy expended in non-vigorous activities and incidence of type II diabetes. ${ }^{13}$ This ties in with the finding that glucose intolerance is less common in individuals reporting high total levels of physical activity (expressed as METs per hour per week). ${ }^{23}$ In the latter study, most of the activity for men was occupational (and therefore probably not undertaken in long continuous spells), whereas for women regular walking (not for formal exercise) was the commonest activity. Similarly, in the insulin resistance atherosclerosis study, levels of expenditure in non-vigorous activities (3.5-5 METs, typically home maintenance, gardening, indoor household chores, brisk walking) were positively related to insulin sensitivity, independent of vigorous activity. ${ }^{24}$

A high level of physical activity has recently been associated with reduced risk of colon cancer. For example, in Norwegian women, leisure time activity equivalent to walking or cycling for at least four hours a week was associated with a $38 \%$ decrease in risk. ${ }^{15}$ In the US nurses health study, women active at a level of 3-6 METs (moderate activity) for more than one hour a day had a $46 \%$ lower risk than those who participated in these activities at a lower level; walking was the commonest type of leisure activity in these women, and therefore a major contributor to the totals of moderate exercise. $^{25}$

Thus aspects of the epidemiological evidence in different populations suggest that physical activity need not be performed in rather long, say 20 minutes or more, sessions in order to confer a variety (and expanding list) of health gains. Until data are published on the duration of the sessions of activities likely to be performed on an intermittent basis, however, this evidence does not constitute a sufficient rationale for the proposition that physical activity can be accumulated through the day in several short sessions.

\section{Multiple short sessions of activity as a means of improving fitness}

The idea that sporadic bouts of activity will be an adequate stimulus to health benefits comes also from studies that have systematically compared the effects of shorter bouts of activity spread throughout the day with those of longer bouts. Two studies are consistently cited in the statements of expert panels, ${ }^{4-6}$ namely those of deBusk and colleagues ${ }^{26}$ and Ebisu. ${ }^{27}$ In the former, 36 sedentary middle aged men performed either one 30 minute session of jogging or three 10 minute sessions on five days a week for eight weeks; the intensity of exercise was $65-75 \%$ of maximal heart rate (equivalent to $55-65 \%$ of $\left.\dot{\mathrm{V}}_{2} \mathrm{MAX}\right) .{ }^{26}$ Men were allocated randomly to the different patterns of exercise but there was no control group. Although both groups of joggers showed similar decreases in heart rate during a standard submaximal treadmill test, the increase in $\dot{\mathrm{V}}_{\mathrm{O}_{\text {MAX }}}$ was significantly greater for the long bout group (4.4 $\mathrm{ml} / \mathrm{kg} / \mathrm{min}, 13.9 \%$ ) than for the short bout group $(2.5 \mathrm{ml} / \mathrm{kg} / \mathrm{min}, 7.6 \%)$. Decreases in body mass were similar $(1.75 \mathrm{~kg}$ and $1.79 \mathrm{~kg}$ respectively).

The second frequently cited study compared effects of different running training regimens on endurance fitness and blood lipids. ${ }^{27}$ The subjects were 53 young men, randomly assigned to four different groups. Three groups ran equivalent distances on three days a week for 10 weeks, in one, two, or three separate sessions, and responses were compared with those of a control group who did not train. Runners completing three sessions a day probably exercised for about eight minutes per session early in the training period, rising to about 16 minutes for the last three weeks. $\dot{\mathrm{V}}_{2} \mathrm{MAX}$ increased significantly in all training groups-by $3.9-5.6 \mathrm{ml} / \mathrm{kg} / \mathrm{min} \quad(6.9-9.8 \%)$ from initial values of the order of $55 \mathrm{ml} / \mathrm{kg} / \mathrm{min}$. $\mathrm{Ebisu}^{27}$ also report a significant increase (pre-training $v$ post-training, within group) in high density lipoprotein (HDL) cholesterol of $0.12 \mathrm{mmol} / 1(9.6 \%)$ in the group training three times a day. It should be noted, however, that HDL cholesterol increased also in the control group (by $0.04 \mathrm{mmol} / 1,3.4 \%$ ) and that the investigators do not appear to have compared change in the intervention group with change in controls - that is, the more rigorous test of a change with training.

Recently, three other papers comparing the efficacy of different physical activity patterns have been published. Jakicic and colleagues ${ }^{28}$ studied overweight women over 20 weeks. Subjects were randomly assigned to one of two groups: long bout exercise or short bout exercise. All subjects undertook aerobic exercise five days a week, "primarily walking". The prescription for long bout walkers was one session of 20 minutes, increasing over nine weeks to 40 minutes; short bout walkers were prescribed two, progressing to four, 10 minute sessions per day. Predicted $\dot{\mathrm{V}}_{2} \mathrm{MAX}$ increased to a similar degree in both walking groupsthat is, by $5.6 \%$ and $5.0 \%$ for long and short bout groups respectively. Both groups lost significant amounts of body weight, with a tendency for loss to be greater in the short bout group (8.9 (5.3) $\mathrm{kg} v 6.4(4.5) \mathrm{kg}, \mathrm{p}<0.07)$. As a consequence of better adherence to the prescription, the short bout group exercised on more days and for a longer total time (224 (70) $\mathrm{min} /$ week $v 188$ (58) $\mathrm{min} /$ week) than the long bout group. However, (theoretically) the difference in weight loss between the groups was greater than could be attributed to the difference in exercise energy expenditure.

In a longer study, 13 obese women walked briskly ( $52 \%$ of heart rate reserve) for $10 \mathrm{~min}$ utes three times a day on five days a week for 32 weeks. ${ }^{29}$ Fasting blood lipids, insulin, and glucose were measured, in addition to peak oxygen uptake and body composition. For the group as a whole, there were no changes in body mass, $\dot{\mathrm{V}}_{2} \mathrm{MAX}$, or serum concentrations 
of total, HDL or low density lipoprotein (LDL) cholesterol, or triacylglycerol (TAG). However, there were indications that individuals who were older, fatter, and particularly unfit at baseline adapted to the exercise regimen with a loss of fat weight, improved $\dot{\mathrm{V}}_{2} \mathrm{MAX}$, and a decrease in fasting insulin. As in the earlier study from the same group, ${ }^{28}$ adherence to the intermittent pattern of moderate exercise was good $(\sim 86 \%)$ and better than might be expected for prescriptions involving longer continuous exercise sessions.

A study using a similar design, but incorporating a control group, was undertaken by my research group; sedentary middle aged women who were, on average, towards the top end of the desirable range of weight for height were studied over ten weeks. ${ }^{30}$ Women following the exercise regimens were randomly assigned to perform on five days each week either one 30 minute session of brisk walking or three 10 minute sessions. The intensity of exercise was $70-80 \%$ of maximal heart rate, $60-70 \%$ of $\dot{\mathrm{V}}_{2} \mathrm{MAX}$. $\dot{\mathrm{V}}_{2} \mathrm{MAX}$ increased by the same amount in each of the walking groups $(\sim 2.3$ $\mathrm{ml} / \mathrm{kg} / \mathrm{min}$ or $8 \%$ ), but only the short bout group showed a significant decrease in body weight and waist circumference relative to controls.

Experimental evidence for the recommendation that accumulation of short bouts of activity is one approach to a desirable physical activity goal is thus scanty. Only one of the five studies above compared changes in exercisers with changes in controls in assessing the responses to training ${ }^{30}$; the total number of subjects studied is small $(\sim 190)$; only two studies provide (limited) information on health gains other than changes in aerobic fitness and body weight/fatness. ${ }^{27}{ }^{29}$ However, with patterns of activity based on short sessions-typically 8-15 minutes in duration - of activity a day, four out of five studies found improvements in fitness, ${ }^{26-28}{ }^{30}$ and three found decreases in body weight and/or fatness. ${ }^{26} 2830$ The improvements in fitness and decreases in body weight after multiple short bouts of brisk walking-an activity specifically mentioned in recommendations from expert panels ${ }^{4}$ - support the suggestion that this activity should be the cornerstone of a generally active lifestyle. ${ }^{31}$

For sedentary middle aged subjects, gains in fitness with multiple bouts were similar to gains achieved through longer continuous bouts of equivalent duration in the study of Murphy and Hardman. ${ }^{30}$ By contrast, deBusk and colleagues $^{26}$ found a significantly greater increase in $\dot{\mathrm{V}}_{2} \mathrm{MAX}$ for the men who performed the longer exercise sessions. Training intensity has a direct impact on the magnitude of improvements in fitness so one reason could be that long bout joggers spent a greater proportion of training time above the recommended heart rate range than short bout joggers $(33 \% v 17 \%)$. This may reflect the fact that, in untrained people, heart rate rises progressively during exercise, and walkers monitoring heart rate can slow their pace to oppose this rise whereas joggers with low
$\dot{\mathrm{V}}_{2} \mathrm{MAX}$ values may not be able to do this without changing their gait to walking.

Until more information is available, the issue of whether there is an interaction of exercise intensity with exercise pattern cannot be resolved. As moderate intensity exercise is recommended for sedentary individuals taking up exercise-because vigorous exercise is hazardous for them ${ }^{32}$ - this needs to be done. It can be estimated that the intensity of activity in the studies on accumulation of activity was between 55 and $70 \%$ of $\dot{\mathrm{V}}_{2} \mathrm{MAX}$ - that is, moderate to moderately vigorous. Many presently sedentary individuals do not exert themselves above $30-35 \%$ of their $\dot{\mathrm{V}}_{2} \mathrm{MAX},{ }^{33}$ so it may be speculated that exercise below this threshold of intensity could elicit improvements in their fitness. It should be mentioned that, even if the improvements in fitness through short bouts are somewhat less than those acquired through longer bouts, they may be sufficient to confer important, if not optimal, health gains; in at least one data set, the major difference in mortality risk was found between men and women in the lowest quintile for fitness and those in the next highest quintile. ${ }^{34}$

The limited data available show that several short bouts of activity a day are at least as effective as one longer bout as far as weight regulation is concerned, ${ }^{26}{ }^{28}{ }^{30}$ in line with the view that the total energy expenditure of exercise is the most important determinant of exercise induced weight loss. ${ }^{35}$ There are indications, however, in two of these studies of more weight loss with short bouts than with equivalent exercise in longer bouts. ${ }^{28}{ }^{30}$ One possibility is that exercising in short bouts may, for practical reasons, restrict energy intake; subjects performing short bouts of exercise may do so in their lunch hour, restricting the time available for eating.

\section{Importance of energy expenditure}

Examination of the way physical activity has been measured and reported in studies such as the Harvard alumni study ${ }^{12}$ and the multiple risk factor intervention trial ${ }^{19}$ leads to the possibility that benefits were mainly linked to the total amount of energy expended. This does not preclude the possibility of additional benefit from sustained activity; indeed Paffenbarger has been quoted as saying that, among men who expended the same amount of energy weekly, those who performed some form of sustained exercise had significantly lower death and heart attack rates than those who did not $^{36}$-although I am not aware of any published data on this.

It is, however, plausible that at least some of the benefit of activity is achieved through the associated increases in energy expenditure. Recently, the concept of metabolic fitness has been introduced ${ }^{37}$ in an attempt to highlight the multiple metabolic benefits of considerable amounts of low intensity exercise, taken on an almost daily basis, and which have been shown experimentally to be independent of changes in cardiorespiratory fitness as assessed by $\dot{\mathrm{V}} \mathrm{O}_{2} \mathrm{MAX}$. The metabolic variables in question include insulin sensitivity, low levels of plasma 
TAG, and high plasma levels of HDL cholesterol. Changes in these have been closely associated with decreases in body fatness, particularly loss of abdominal fat, ${ }^{38}$ but low intensity training in the absence of fat loss can also stimulate changes in lipoprotein metabolism and insulin sensitivity. ${ }^{39}$ The latter finding points to a benefit from improved energy turnover per se, and so fits well with recent observations that overweight men who are fit have a lower risk of premature death than those of normal weight who are unfit. ${ }^{40}$

In addition to the study of Ebisu referred to above ${ }^{27}$ one intervention study has shown that exercise induced changes in blood lipids may be related to the energy expenditure of exercise. Three groups of premenopausal women were studied in a randomised trial over 24 weeks; exercisers walked three miles on five days a week at 3, 4, or $5 \mathrm{mph} .{ }^{41}$ Improvements in $\dot{\mathrm{V}}_{2} \mathrm{MAX}$ were related to the intensity of regular walking but changes in serum levels of total cholesterol, LDL cholesterol, HDL cholesterol, and TAG did not differ significantly between the exercise groups. Specifically, women who took five hours to walk 15 miles regularly experienced the same level of increase in HDL cholesterol as those who took three hours.

Plasma HDL concentrations may constitute a "metabolic memory" for ability to degrade TAG rich lipoproteins. ${ }^{41}$ The basis of this view is that hydrolysis of TAG by lipoprotein lipase "slims down" these particles, leading to an excess of surface proteins. Some of these are rapidly acquired by nascent HDL, which become mature spherical particles in the process. Consequently, the concentrations in plasma of HDL and TAG are inversely related. If the capacity to metabolise TAG is low, the residence time in the circulation of TAG rich lipoproteins is increased, enhancing the opportunity for exchange of core lipid with the cholesterol rich lipoproteins, which not only impairs reverse cholesterol transport but also leads to a preponderance of small dense (atherogenic) LDLs. If the capacity to metabolise TAG is low, the postprandial rise in plasma TAG concentration will be high. People spend most of their lives in the postprandial state, so repeated episodes of exaggerated postprandial lipaemia may hasten the progression of atherosclerosis, a proposition supported by studies showing higher levels of postprandial lipaemia in men with known coronary artery disease than in healthy controls. ${ }^{42}$

Exercise has short term and possibly long term effects in reducing postprandial lipaemia. ${ }^{43-45}$ There is evidence that energy expenditure per se is an important determinant of the acute decrease in lipaemia evident after exercise. The findings of studies from my laboratory are pertinent. These employed within subject comparisons of the lipaemic response to a standard oral fat load consumed 16-18 hours after an exercise session. As might be expected, moderate intensity exercise $(60 \%$ $\dot{\mathrm{V}} \mathrm{O}_{2} \mathrm{MAX}$ ) caused a greater decrease in lipaemia than an equivalent period of low intensity exercise $\left(30 \% \dot{\mathrm{V}}_{2} \mathrm{MAX}\right) .{ }^{46}$ However, when the dura- tion of low intensity exercise was increased so that the energy expended was the same as in the moderate intensity trial-that is, trading intensity for duration (1.5 hours at $60 \%$ $\dot{\mathrm{V}}_{2} \mathrm{MAX} v$ three hours at $\left.30 \% \dot{\mathrm{V}}_{2} \mathrm{MAX}\right)$ - each bout of exercise reduced lipaemia to the same degree. ${ }^{47}$ The pattern of prior exercise does not seem to make an important difference to its effect on subsequent lipaemia, at least when a considerable amount of energy is expended. In a recent study young men undertook three oral fat tolerance tests: on the day preceding one test they refrained from exercise; before another they performed 90 minutes of exercise at $60 \%$ of $\dot{\mathrm{VO}}_{2} \mathrm{MAX}$ in one continuous bout; before another, they performed three separate 30 minute sessions at intervals of several hours, expending the same energy. Exercise reduced postprandial lipaemia to the same degree, irrespective of its pattern. ${ }^{48}$

There does seem to be a relation between energy expended and the ensuing reduction in lipaemia. When subjects walked at $50 \%$ $\dot{\mathrm{V}} \mathrm{O}_{2} \mathrm{MAX}$ for one hour on the afternoon before a fat tolerance test, their total lipaemic response (assessed as the area under the plasma concentration $v$ time curve over six hours) was $12.5 \%$ lower than in a control (no exercise) trial; when the exercise period was extended to two hours, the decrease in lipaemia was increased twofold-that is, $23 \%{ }^{49}$ Plasma concentrations of heparin releasable lipoprotein lipase were 27 and $32 \%$ higher than the control at the end of the fat tolerance tests. ${ }^{49}$

Collectively, these findings suggest that the effect of a session of exercise on postprandial lipaemia is closely linked to energy expenditure, perhaps through some mechanism related to muscle contraction and mediated through changes in the expression of muscle proteins related to substrate acquisition in the exercised muscle. Skeletal muscle lipoprotein lipase, like other proteins critical to the transport and metabolism of energy substrates for muscle, increases rapidly but transiently after exercise..$^{50}$

Aspects of the epidemiological evidence for improved insulin/glucose dynamics and a lower risk of developing type II diabetes among regular exercisers were referred to above. Experimental studies have shown that enhanced insulin sensitivity is a "genuine response to training but short lived", ${ }^{51}$ persisting for a few days only when training is interrupted. ${ }^{52}$ Like the effects on postprandial lipoproteins, the short term effect of exercise on insulin sensitivity appears to be linked to energy expenditure. In one study, indices of insulin sensitivity were measured for eight women with type II diabetes in each of three conditions: after low intensity exercise at $50 \% \dot{\mathrm{V}}_{2} \mathrm{MAX}$; after high intensity exercise at $75 \% \dot{\mathrm{V}}_{2} \mathrm{MAX}$; after a period without exercise (control). ${ }^{53}$ The duration of exercise was adjusted so that energy expenditure was the same for the two exercise conditions. Insulin sensitivity was enhanced in an identical way by each exercise pattern, again suggesting that low intensity exercise can stimulate the same metabolic changes after exercise as high intensity exercise, provided that the same energy is expended. 
Thus the energy expenditure of regular exercise appears to be an important determinant of at least some metabolic adaptations that might be expected to confer a reduced risk of cardiovascular and metabolic disease. This is in line with observations that metabolic improvements (decrease in LDL cholesterol, increase in $\mathrm{HDL}_{2}$ cholesterol, ratio of insulin to glucose areas measured during an oral glucose tolerance test) correlate significantly with losses of total and abdominal visceral fat rather than with the increase in $\dot{\mathrm{V}}_{2} \mathrm{MAX}$. $^{38}$

\section{Skeletal health}

Mechanical loading is an important determinant of bone mass and architecture, ${ }^{54}$ and the influence of increased physical activity on bone has been much studied. This is one area where the accumulation of exercise throughout the day must theoretically be an effective pattern. An osteogenic stimulus arises when bone is exposed to unusual dynamic strain distribution. This effect is quickly "saturated" however, so that there is little extra stimulus to bone formation from high numbers of load cycles. The relevance of this finding is that the structural competence of bone can be maintained by comparatively infrequent loading events and does not require long periods of repetitive activity. ${ }^{55}$ This thinking fits well with findings of increased bone mineral density in premenopausal women after a daily exercise regimen of 50 vertical jumps. ${ }^{56}$ If strain magnitude and strain nature are the determinants of the osteogenic response to exercise, then several brief periods during a day of high impact exercises will in fact be more effective than long periods of endurance type exercise where the applied loads are typically low.

\section{Walking and cycling as a means of commuting to work}

One obvious way to accumulate physical activity regularly is to commute to and from work by bicycle or on foot. A year round commitment to this means at least two exercise sessions five days a week for most weeks of the year. The energy expenditure can be considerable and invariably greater than that achieved through planned exercise.

Researchers in Finland have studied physically active commuting to work. An initial survey showed that walking or bicycling to work offered "basic habitual exercise" to about one third of the employed urban population. The activity was reported to be "regular, frequent, rather stable year round and brisk in tempo". ${ }^{57}$ A randomised controlled intervention trial was subsequently conducted in healthy men and women who were not regular leisure time exercisers. The mean one way commuting distance was 2 miles for walkers and 6 miles for cyclists. Walkers selected a speed typically equivalent to $53 \% \dot{\mathrm{V}}_{2} \mathrm{MAX}$ and cyclists closer to $63 \% \dot{\mathrm{V}}_{2} \mathrm{MAX}$. On average, ten weeks of active commuting resulted in a $4.5 \%$ net (compared with control) increase in $\dot{\mathrm{V}}_{2} \mathrm{MAX}$ $(\mathrm{p}=0.02)$ and a $5 \%$ net increase in HDL cholesterol $(p=0.06)$. These studies do not provide evidence for the accumulation of bouts of activity as short as 10 minutes, however, because the journeys lasted about 30 minutes.

The regularity and frequency of physically active commuting to work make it an ideal form of exercise likely to maintain short term metabolic effects afterwards: no special clothing is needed (activities that require changing are not likely to be undertaken several times a day); the time commitment is minimised because one has in any case to travel to work; and it requires no special skills. The barriers are of course bad weather, poor conditions of pedestrian and cycling routes, and fear of accidents.

\section{Concluding remarks}

The argument for accumulation of short bouts of physical activity is predicated largely on the assertion that total energy expenditure is the important determinant of health gains and there is epidemiological evidence for this. A major weakness of this evidence is, however, that there are no data describing the typical duration of sessions of moderate intensity activity likely to have been performed on an intermittent basis on which to assess their contribution to total exercise energy expenditure.

Improvements in fitness probably confer health benefits. Experimental data showing the effectiveness of several short bouts of moderate intensity physical activity in improving fitness are few. ${ }^{28}{ }^{30}$ This is an important gap in the evidence because if activity is to be accumulated through several short sessions it must necessarily be non-sporting and of moderate intensity. On the whole, people will not change into special clothing, travel to a facility, and engage in planned vigorous exercise several times in one day. The debate about the accumulation issue cannot therefore be separated from that about the intensity issue - that is, is moderate intensity exercise (3-6 METs) sufficient to confer health gains? $?^{58}$

Intuitively the length of a session of physical activity must influence its potential to confer metabolic adaptations relevant to cardiovascular risk. Indeed aspects of observational studies referred to above make it clear that sustained periods of exercise are probably associated with greater benefits. However, in the absence of data to indicate that, say, three short bouts of activity are equivalent to one longer bout in terms of reducing disease risk, this aspect of current US recommendations is speculative. Of course, this should not obscure the vital issue of the need to address the public health burden in this country attributable to physical inactivity. There is no evidence that adopting a habit of frequent 10-15 minute bouts of physical activity spread throughout the day will harm a sedentary individual, and some evidence that it may be of benefit. Moreover, such a prescription avoids the risks of unaccustomed vigorous exercise by ensuring that activity is moderate in intensity. 
1 National Fitness Survey: Main Findings. Sports Council and Health Education Authority, 1992.

Merontion of coronary heart disease: today's best buy in public health. Med Sci Sports Exerc 1994;26:807-14.

3 Department of Health. More people, more active, more often. Report of Physical Activity Task Force. Department of Health, 1995

4 Pate RR, Pratt M, Blair SN, et al. Physical activity and public health. A recommendation from the Centers for Disease
Control and Prevention and the American College of Sports Medicine. FAMA 1995;273:402-7.

5 Physical activity and health: a report of the Surgeon General. Atlanta: US Departments of Health and Human Services Centers for Disease Control and Prevention, 1996.

6 National Institute of Health Consensus Development Panel. Physical activity and cardiovascular health. $\mathcal{F} A M A$ 1996; 276:241-6.

7 Blair SN, Goodyear NN, Gibbons LW, et al. Physical fitness and incidence of hypertension in healthy normotensive and incidence of hypertension in healthy

8 Sandvik L, Erikssen J, Thaulow E, et al. Physical fitness as a predictor of mortality among healthy, middle-aged Norwepredictor of mortality among healthy, mid

9 Blair SN, Kampert JB, Kohl HW, et al. Influences of cardiorespiratory fitness and other precursors on cardiovascula disease and all-cause mortality in men and women. $\mathcal{F A M A}$ 1996;276:205-10.

10 Lynch J, Helmrich SP, Lakka TA, et al. Moderately intense physical activities and high levels of cardiorespiratory fitness reduce the risk of non-insulin-dependent diabetes mellitus in middle-aged men. Arch Intern Med 1996;156: 1307-14.

11 Haapanen N, Miilunpalo S, Vuori I, et al. Characteristics of leisure time physical activity associated with decreased risk in middle-aged men. Am f Epidemiol 1996;143:870-80.

12 Paffenbarger RS, Hyde RT, Wing AL, et al. Physical activity, all-cause mortality, and longevity of college alumni. $N$ Engl all-cause mortality, and lo

13 Helmrich SP, Ragland DR, Leung RW, et al. Physical activity and reduced occurrence of non-insulin-dependent ity and reduced occurrence of non-insulin-depen
diabetes mellitus. N Engl f Med 1991;325:147-52.

14 Paffenbarger RS, Wing AL, Hyde RT, et al. Physical activity and incidence of hypertension in college alumni. Am $\mathcal{F} E p$ demiol 1983;117:247-57.

15 Thune I, Lund E. Physical activity and risk of colorectal cancer in men and women. Br f Cancer 1996;73:1134-40.

16 Thune I, Brenn T, Lund E, et al. Physical activity and the risk of breast cancer. N Engl f Med 1997;336:1269-75.

17 Shaper AG, Wannamethee G. Physical activity and ischaemic heart disease in middle-aged British men. Br Heart $\mathcal{F}$ 1991;66:384-94.

18 Magnus K, Matroos A, Strackee J. Walking, cycling, or gardening, with or without seasonal interruption, in relation to coronary events. Am f Epidemiol 1979;110:724-33.

19 Leon AS, Connett J, Jacobs DR, et al. Leisure-time physical activity levels and risk of coronary heart disease and death: the multiple risk factor intervention trial. $¥ A M A 1987 ; 258$ : the multiple

20 Paffenbarger RS, Hyde RT, Wing AL, et al. The association of changes in physical activity level and other lifestyle characteristics with mortality among men. N Engl f Med 1993; 328:538-45.

21 Hakim AA, Petrovitch H, Burchfiel CM, et al. Effects of walking on mortality among nonsmoking retired men. $N$ Engl F Med 1998;338:94-9.

22 Lemaitre RN, Heckbert SR, Psaty BM, et al. Leisure-time physical activity and the risk of nonfatal myocardial infarction in postmenopausal women. Arch Intern Med 1995;155: 2302-8.

23 Pereira MA, Kriska AM, Joswiak ML, et al. Physical inactivity and glucose intolerance in the multiethnic island of Mauritius. Med Sci Sports Exerc 1995;27:1626-34.

24 Mayer-Davis EJ, D'Agostino R, Karter AJ, et al. Intensity and amount of physical activity in relation to insulin sensitivity. The insulin resistance atherosclerosis study. $7 A M A$ tivity. The insulin re

25 Martínez ME, Giovannucci E, Spiegelman D, et al. Leisuretime physical activity, body size, and colon cancer in women. F Natl Cancer Inst 1997;89:948-55.

26 DeBusk RF, Stenestrand U, Sheehan M, et al. Training effects of long versus short bouts of exercise in healthy subjects. Am ₹ Cardiol 1990;65:1010-13.

27 Ebisu T. Splitting the distance of endurance running: on cardiovascular endurance and blood lipids. Fapanese Fournal of Physical Exercise 1985;30:37-43.

28 Jakicic JM, Wing RR, Butler BA, et al. Prescribing exercise in multiple short bouts versus one continuous bout: effects on adherence, cardiorespiratory fitness, and weight loss in overweight women. Int $\mathcal{7}$ Obes 1995;19:893-901.

29 Snyder KA, Donnelly JE, Jabobsen dJ, et al. The effects of long-term, moderate intensity, intermittent exercise on aerobic capacity, body composition, blood lipids, insulin and glucose in overweight females. Int $\mathcal{F}$ Obes 1997;21: 1180-9.
30 Murphy $\mathrm{MH}$, Hardman AE. Training effects of short and ong bouts of brisk walking in sedentary women. Med Sci Sports Exerc 1998;30:152-7.

31 Morris JN, Hardman AE. Walking to health. Sports Med 1997;23:306-32.

32 Mittleman MA, Maclure M, Tofler GH, et al. Triggering of cute myocardial infarction by heavy physical exertion. Protection against triggering by regular exertion. $N$ Engl $\mathscr{f}$ Med 1993;329:1677-83.

33 Haskell WL. Dose-response issues from a biological perspective. In: Bouchard C, Shephard RJ, Stephens T, ed. Physical activity, fitness and health. Champaign, IL: Human Kinetics, 1994:1030-9.

34 Blair SN, Kohl HW, Paffenbarger RS, et al. Physical fitness and all-cause mortality: a prospective study of healthy men and women. $7 A M A 1989 ; 262: 2395-401$.

35 Ballor DL, Keesey RE. A meta-analysis of the factors affecting exercise-induced changes in body mass, fat mass and at-free mass in males and females. Int f Obes 1991;15:71726.

36 Barinaga M. How much pain for cardiac gain? Science 1997; 276:1324-7.

37 Després J-P, Lamarche B. Low-intensity endurance exercise training, plasma lipoproteins and the risk of coronary heart disease. F Intern Med 1994;236:7-22.

38 Després J-P, Pouliot MC, Moorjani S, et al. Loss of abdominal fat and metabolic response to exercise training in obese women. Am F Physiol 1991;261:E159-67.

39 Oshida Y, Yamanouchi K, Haymamizu S, et al. Long-term mild jogging increases insulin action despite no influence on body mass index or $\dot{\mathrm{V}}_{2} \mathrm{MAX}$. F Appl Physiol 1989;66: 2206-10.

40 Lee CD, Jackson AS, Blair SN. US weight guidelines: is it also important to consider cardiorespiratory fitness? Int $\mathcal{F}$ Obes 1998; 22(Suppl 2):S2-7.

41 Duncan JJ, Gordon NF, Scott CB. Women walking for health and fitness. How much is enough? fAMA 1991;266: 3295-9.

42 Patsch JR, Miesenböck G, Hopferwieser T, et al. Relation of triglyceride metabolism and coronary artery disease. Studies in the postprandial state. Arterioscler Thromb 1992;12: $1336-45$.

43 Weintraub MS, Rosen Y, Otto R, et al. Physical conditioning in the absence of weight loss reduces fasting and postprandial triglyceride-rich lipoprotein levels. Circulation 1989;79: 1007-14

44 Aldred HE, Perry I, Hardman AE. The effect of a single bout of brisk walking on postprandial lipemia in normolipidemic young adults. Metabolism 1994;43:836-41.

45 Podl TR, Zmuda JM, Yurgalevitch SM, et al. Lipoprotein lipase activity and plasma triglyceride clearance are elevated in endurance-trained women. Metabolism 1994; 43:808-13.

46 Tsetsonis NV, Hardman AE. Effects of low and moderate intensity treadmill walking on postprandial lipaemia in healthy young adults. Eur f Appl Physiol 1996;73:419-26.

47 Tsetsonis NV, Hardman AE. Reduction in postprandial lipemia after walking: influence of exercise intensity. Med Sci Sports Exerc 1996;28:1235-42.

48 Gill JMR, Murphy MH, Hardman AE. Postprandial lipemia: effects of intermittent versus continuous exercise. Med Sci Sports Exerc 1998;30:1515-20.

49 Herd SL, Hardman AE, Vora V. Influence of brisk walking duration on postprandial lipemia and plasma lipoprotein lipase activity. Med Sci Sports Exerc 1997;29:S6.

50 Seip RL, Mair D, Cole TG, et al. Induction of human skeletal muscle lipoprotein lipase gene expression by shortterm exercise is transient. Am 7 Physiol 1997;272:E255-61.

51 Dela F, Mikines KJ, von Linstow M, et al. Effect of training on insulin-mediated glucose uptake in human muscle. Am F Physiol 1992;263:E1134-43.

52 King DS, Baldus RJ, Sharp RL, et al. Time course for exercise-induced alterations in insulin action and glucose tolerance in middle-aged people. F Appl Physiol 1995;78: $17-22$.

53 Braun B, Zimmermann MB, Kretchmer N. Effects of exercise intensity on insulin sensitivity in women with non-insulin-dependent diabetes mellitus. f Appl Physiol 1995;78:300-6.

54 Lanyon LE. Using functional loading to influence bone mass and architecture: objectives, mechanisms, and relationship with estrogen of the mechanically adaptive process in bone. Bone 1996;18:37S-43S.

55 Rubin CT, Lanyon LE. Regulation of bone formation by applied dynamic loads. F Bone foint Surg [Am] 1984;66: 397-402.

56 Bassey EJ, Ramsdale SJ. Increase in femoral bone density in young women following high-impact exercise. Osteoporo Int $1994 ; 4: 72-5$

57 Vuori IM, Oja P, Paronen O. Physically active commuting to work - testing its potential for exercise promotion. $\mathrm{Med} S \mathrm{Sc}$ Sports Exerc 1994;26:844-50.

58 Blair SN, Connelly JC. How much physical activity should we do? Res Q Exerc Sport 1996;67:193-205. 